\title{
Mitochondrial genomes reveal an explosive radiation of extinct and extant bears near the Miocene-Pliocene boundary
} Johannes Krause ${ }^{1}$, Tina Unger1, Aline Noçon ${ }^{1}$, Anna-Sapfo Malaspinas², Sergios-Orestis Kolokotronis ${ }^{3,4}$, Mathias Stiller ${ }^{1}$, Leopoldo Soibelzon ${ }^{5}$, Helen Spriggs ${ }^{6}$, Paul H Dear ${ }^{6}$, Adrian W Briggs ${ }^{1}$, Sarah CE Bray ${ }^{7}$, Stephen J O'Brien ${ }^{8}$, Gernot Rabeder ${ }^{9}$, Paul Matheus ${ }^{10}$, Alan Cooper ${ }^{7}$, Montgomery Slatkin ${ }^{2}$, Svante Pääbo ${ }^{1}$ and Michael Hofreiter*1

\footnotetext{
Address: ${ }^{1}$ Max Planck Institute for Evolutionary Anthropology, Deutscher Platz 6, D-04103 Leipzig, Germany, ${ }^{2}$ Department of Integrative Biology, University of California, Berkeley, CA 94720-3140, USA, ${ }^{3}$ Department of Ecology, Evolution and Environmental Biology, Columbia University, 1200 Amsterdam Avenue, MC5557, New York, NY 10027, USA, ${ }^{4}$ Sackler Institute for Comparative Genomics, American Museum of Natural History, Central Park West at 79th Street, New York, NY 10024, USA, ${ }^{5}$ Departamento Científico Paleontologia de Vertebrados, Museo de La Plata. Paseo del Bosque, (1900) La Plata, Buenos Aires, Argentina, ${ }^{6} \mathrm{MRC}$ Laboratory of Molecular Biology, Hills Road, Cambridge, CB2 2QH, UK, ${ }^{7}$ Australian Centre for Ancient DNA, School of Earth and Environmental Sciences, University of Adelaide, Adelaide, SA 5005, Australia, ${ }^{8}$ Laboratory of Genomic Diversity, National Cancer Institute, Frederick, MD 21702-1201, USA, ${ }^{9}$ Department of Paleontology, University of Vienna, 1090 Vienna, Austria and ${ }^{10}$ Alaska Quaternary Center, University of Alaska Fairbanks, Fairbanks, AK 99775, USA

Email: Johannes Krause - krause@eva.mpg.de; Tina Unger - tina.unger@medizin.uni-leipzig.de; Aline Noçon - nocon@eva.mpg.de; AnnaSapfo Malaspinas - sapfo@berkeley.edu; Sergios-Orestis Kolokotronis - koloko@amnh.org; Mathias Stiller - stiller@eva.mpg.de; Leopoldo Soibelzon - lsoibelzon@fcnym.unlp.edu.ar; Helen Spriggs - hs397@cam.ac.uk; Paul H Dear - phd@mrc-lmb.cam.ac.uk; Adrian W Briggs - briggs@eva.mpg.de; Sarah CE Bray - sarah.bray@adelaide.edu.au; Stephen J O'Brien - obrien@ncifcrf.gov; Gernot Rabeder - gernot.rabeder@univie.ac.at; Paul Matheus - matheus@northwestel.net; Alan Cooper - alan.cooper@adelaide.edu.au; Montgomery Slatkin - slatkin@socrates.berkeley.edu; Svante Pääbo - paabo@eva.mpg.de; Michael Hofreiter* - hofreite@eva.mpg.de

* Corresponding author
}

Published: 28 July 2008

BMC Evolutionary Biology 2008, 8:220 doi:10.1 186/147/-2148-8-220

This article is available from: http://www.biomedcentral.com/l47I-2/48/8/220

(c) 2008 Krause et al; licensee BioMed Central Ltd.

This is an Open Access article distributed under the terms of the Creative Commons Attribution License (http://creativecommons.org/licenses/by/2.0), which permits unrestricted use, distribution, and reproduction in any medium, provided the original work is properly cited.

\begin{abstract}
Background: Despite being one of the most studied families within the Carnivora, the phylogenetic relationships among the members of the bear family (Ursidae) have long remained unclear. Widely divergent topologies have been suggested based on various data sets and methods.

Results: We present a fully resolved phylogeny for ursids based on ten complete mitochondrial genome sequences from all eight living and two recently extinct bear species, the European cave bear (Ursus spelaeus) and the American giant short-faced bear (Arctodus simus). The mitogenomic data yield a well-resolved topology for ursids, with the sloth bear at the basal position within the genus Ursus. The sun bear is the sister taxon to both the American and Asian black bears, and this clade is the sister clade of cave bear, brown bear and polar bear confirming a recent study on bear mitochondrial genomes.

Conclusion: Sequences from extinct bears represent the third and fourth Pleistocene species for which complete mitochondrial genomes have been sequenced. Moreover, the cave bear specimen demonstrates that mitogenomic studies can be applied to Pleistocene fossils that have not been preserved in permafrost, and therefore have a broad application within ancient DNA research. Molecular dating of the mtDNA divergence times suggests a rapid radiation of bears in both the Old and New Worlds around 5 million years ago, at the Miocene-Pliocene boundary. This coincides with major global changes, such as the Messinian crisis and the first opening of the Bering Strait, and suggests a global influence of such events on species radiations.
\end{abstract}




\section{Background}

The bear family (Ursidae) is one of the most studied families within the order Carnivora. Members of this family are present on most continents and occupy a wide range of ecological niches from the arctic ice shelves to tropical rainforests (see Additional File 1, Figure S1a). Despite numerous morphological and molecular studies on the phylogenetic relationship among Ursidae members, no consensus exists with regard to either their phylogeny or their taxonomic nomenclature (Table 1). Most analyses have concentrated on the eight extant bear species: brown bear, American black bear, Asian black bear, polar bear, sun bear, sloth bear, spectacled bear and giant panda (for species names see Table 1). Molecular studies based on mitochondrial and nuclear DNA from modern bears have recently provided convincing evidence about several of the controversial relationships among the bears, such as the basal positions of the giant panda and the spectacled bear in the bear tree [1-4] and the position of the polar bear within the brown bear tree making the later paraphyletic $[5,6]$. However, molecular studies for a long time failed to conclusively resolve the phylogenetic relationships among the members of the bear subfamily Ursinae [5], which includes all living bear species except the giant panda and the spectacled bear, from here on referred to as ursine bears. The phylogenetic uncertainty has resulted in major taxonomic confusion. Based on both morphological and molecular data up to six different genera (Ursus, Helarctos, Euarctos, Selenartos, Thalarctos and Melursus; i.e. one for each species) have been suggested for the extant ursine bears (Table 1).

Recently, a study on mitochondrial genome sequences (mtDNAs) of all extant bears presented for the first time an almost completely resolved bear phylogeny with support for most of the problematic nodes in the bear family tree, except for the position of the sloth bear [4]. This shows that longer sequences are necessary for reconstructing a robust phylogeny $[4,6-9]$. Such large data sets also facilitate the molecular dating of divergence events within a phylogeny [12-14]. To resolve the relationships between the extant and extinct members of the bear family and to date the various divergence events among them, we used the complete mtDNA (consisting of $\sim 17 \mathrm{~kb}$ ) from ten different bear species. In addition to three published modern mtDNAs [10], we amplified and sequenced five modern bear mtDNAs using a 2-step multiplex PCR approach $[9,16]$. We also amplified and sequenced entire mtDNAs from the extinct European cave bear (Ursus spelaeus), believed to belong to the ursine bears [11], and the extinct North American giant short-faced bear (Arctodus simus) (see Additional File 1, Figure S1b), thought to be related to the spectacled bear [12].

\section{Results}

\section{Sequence retrieval}

We retrieved complete mtDNAs from GenBank for three extant bear species: brown bear, American black bear and polar bear (GenBank: NC003427, GenBank: NC003428, GenBank: NC003426). For the remaining five living bear species, we sequenced the entire mtDNA in overlapping fragments using a 2-step multiplex PCR approach [7] and a mixture of direct sequencing and sequencing multiple clones (EMBL:FM177759, EMBL:FM177761, EMBL:FM177763, EMBL:FM177764, EMBL:FM177765). We also obtained the complete mtDNA from the extinct European cave bear using a 44,000 year old bone found in Gamssulzen Cave, Austria. Again, we used a 2-step multiplex approach, but in this case, all PCR products were cloned and multiple clones were sequenced (EMBL:FM177760). Moreover, to ensure sequence accuracy, we determined each sequence position from at least two independent primary PCRs [13]. When we observed a discrepancy between the consensus sequences from each of the two amplifications we performed a third amplification and used the consensus sequence from all three amplifications (see Additional File 1). We used the same approach to sequence the extinct American giant shortfaced bear mtDNA, using a 22,000 year-old calcaneum bone from Eldorado Creek, Canada (EMBL:FM177762). In order to further ascertain that the results obtained are reproducible, samples of both extinct bears were extracted, amplified and sequenced each in an additional laboratory that did not have access to the results obtained

Table I: Taxonomic designations for the bears.

\begin{tabular}{|c|c|c|c|c|c|}
\hline Common name & Eisenberg [72] & $\begin{array}{l}\text { Ewer [73]; Corbet \& } \\
\text { Hill [74] }\end{array}$ & Zhang \& Ryder [75] & $\begin{array}{l}\text { Thenius [76]; } \\
\text { Wozencraft [77] }\end{array}$ & $\begin{array}{l}\text { Hall [28]; Nowak [29]; } \\
\text { Yu [4], this study }\end{array}$ \\
\hline giant panda & Ailuropoda melanoleuca & A. melanoleuca & A. melanoleuca & A. melanoleuca & A. melanoleuca \\
\hline spectacled bear & Tremarctos ornatus & T. ornatus & T. ornatus & T. ornatus & T. ornatus \\
\hline Asian black bear & Selenarctos thibethanus & S. thibethanus & S. thibethanus & Ursus thibethanus & U. thibethanus \\
\hline sloth bear & Melursus ursinus & M. ursinus & M. ursinus & M. ursinus & Ursus ursinus \\
\hline sun bear & Helarctos malayanus & H. malayanus & H. malayanus & H. malayanus & Ursus malayanus \\
\hline polar bear & Thalarctos maritimus & T. maritimus & Ursus maritimus & U. maritimus & U. maritimus \\
\hline American black bear & Ursus americanus & Euarctos americanus & E. americanus & U. americanus & U.americanus \\
\hline brown bear & Ursus arctos & U. arctos & U. arctos & U. arctos & U. arctos \\
\hline
\end{tabular}


in Leipzig. For the cave bear a total of 3,520 bp were independently reproduced in Cambridge and for the American giant short-faced bear a total of $395 \mathrm{bp}$ was replicated in the Australian Centre for Ancient DNA in Adelaide. The consensus sequences for all fragments determined in Cambridge were identical to those determined in Leipzig. The replicated fragments at the Australian Centre for Ancient DNA were identical to the sequence obtained in Leipzig except for a single deletion close to the 5 '-end of the light strand in the first fragment. The sequence for this fragment was obtained by direct sequencing in just one $5^{\prime}$ to $3^{\prime}$ direction on the light strand. Given that sequence accuracy immediately downstream the sequencing primer is low, it is likely that this deletion represents a sequencing artifact.

\section{Phylogenetic analyses}

All ten bear mtDNAs were aligned using the harbor seal (Phoca vitulina) mtDNA as outgroup. Phylogenetic trees were reconstructed using maximum parsimony (MP), maximum likelihood (ML) and Bayesian inference. We recovered the same topology using all above-mentioned optimality criteria (Figure 1 and Table 2). Our results confirm the giant panda's basal position in the bear phylogeny [1-4,14-17] and also place the spectacled bear outside ursine bears. In contrast to previous studies our data was sufficient to resolve the phylogenetic relationships among ursine bears with statistical support for all nodes. The sloth bear falls basal to all other ursine bears, which form a monophyletic group with $85 \%, 93 \%$, and $100 \%$ support (MP symmetric resampling, ML bootstrap, and 1.00 Bayesian posterior probability (PP), respectively). The hypothesis suggesting that the sloth bear is basal to the sun bear and black bear clade (hypothesis 6, see Additional File 1, Figure S2) did not have a significantly worse likelihood (AU test, $p=0.147$ ) than the topology favored by our data

Table 2: Node support values for the mitogenomic phylogeny of the bears.

\begin{tabular}{|c|c|c|c|c|c|}
\hline \multirow[t]{2}{*}{ Node } & \multicolumn{3}{|c|}{ Unpartitioned } & \multicolumn{2}{|c|}{ Partitioned } \\
\hline & MP & $M L$ & Bayesian & $M L$ & Bayesian \\
\hline$t_{3}$ & 100 & 100 & 1.00 & 100 & 1.00 \\
\hline$t_{4}$ & 100 & 100 & 1.00 & 100 & 1.00 \\
\hline$t_{5}$ & 85 & 93 & 1.00 & 93 & 1.00 \\
\hline$t_{6}$ & 100 & 100 & 1.00 & 100 & 1.00 \\
\hline$t_{7}$ & 100 & 100 & 1.00 & 100 & 1.00 \\
\hline$t_{8}$ & 76 & 94 & 1.00 & 97 & 1.00 \\
\hline$t_{9}$ & 99 & 97 & 1.00 & 94 & 1.00 \\
\hline$t_{10}$ & 100 & 100 & 1.00 & 100 & 1.00 \\
\hline
\end{tabular}

Unpartitioned and partitioned phylogenetic analyses in maximum parsimony (MP), maximum likelihood (ML) and Bayesian inference of phylogeny. In partitioned analyses every partition was allowed to evolve under a separate unlinked $\mathrm{GTR}+\Gamma$ substitution model and distinct base frequencies in $\mathrm{ML}$ and Bayesian inference of phylogeny. (sloth bear as the most basal ursine bear; hypothesis 9, see Additional File 1, Figure S2) although it had a slightly higher homoplasy index and a less parsimonious tree $\left(\mathrm{HI}_{\text {best }}=0.389, \mathrm{HI}_{\text {competing }}=0.393 ; \mathrm{TL}_{\text {best }}=10092, \mathrm{TL}_{\text {com }}\right.$ peting $=10157$ ). In a MP analysis, however, this hypothesis (hypothesis 6, see Additional File 1, Figure S2) received significantly less support (Wilcoxon signed-ranks and sign tests, $p<10^{-4}$ ). Thus, we suggest that ursine bears are separated into two sister clades, comprised of three species each with the sloth bear forming the basal branch. The first clade contains cave, brown, and polar bears and is supported by all methods. The second clade is composed of the sun and black bears (American and Asian) and receives varying support values, depending on the tree reconstruction method (76\% MP symmetric resampling, 97\% ML bootstrap, and 1.00 Bayesian PP). Finally, the placement of the extinct American giant short-faced bear as a sister taxon to the spectacled bear is supported in all analyses (100\% bootstrap/symmetric resampling and $1.00 \mathrm{PP}$ in all analyses).

The phylogenetic reconstruction makes evident a difficulty in resolving the relationships within ursine bears. As a matter of fact, most of the internal branches are very short. This observation (Fig. 2) makes it likely that individual genes (or short sequences) may exhibit different tree topologies, as shown for humans, chimpanzees and gorillas [18]. In our case, we notice that individual loci of the mtDNA support different topologies. Genes such as $12 \mathrm{~S}$ rRNA, ND4L, ND5, and ND3 exhibited phylogenetic incongruence with two to four other mitochondrial genes (ILD test, $p \leq 0.05$ ). The highest amount of phylogenetic conflict emerged from partitioning the mtDNA to individual genes and the tRNAs of the two strands (tRNA- and tRNA $^{+}$), but only two nodes showed evidence of hidden conflict in a MP setting (node $t_{3} \mathrm{HBS}=-10$, node $t_{5} \mathrm{HBS}=$ -5). Emerging support was evident for all terminal nodes including the ursine branching point (HBS range: 7-21). Intra-ursine nodes $t_{5}, t_{8}$, and $t_{9}$ were the only nodes to show $<100 \%$ replicate-based support values, a fact that may be owed to the lack of consistent support provided by those genes (PHBS range: -1 to -7 ).

\section{Estimation of divergence times}

We used several fossil calibration points to estimate the mtDNA divergence dates within the bears (see Materials and Methods). The posterior mean of the divergence time between bears and the harbor seal was estimated at 36 million years ago $(\mathrm{Ma})$, which agrees with previous estimates based on both molecular and paleontological data $[12,19]$. However, due to the wide uniform priors we used for the calibration points, the confidence interval (26.547.4 Ma, Table 3) remains large, depending on the type of analysis. The initial divergence within bears occurred between the giant panda and all remaining bears, esti- 


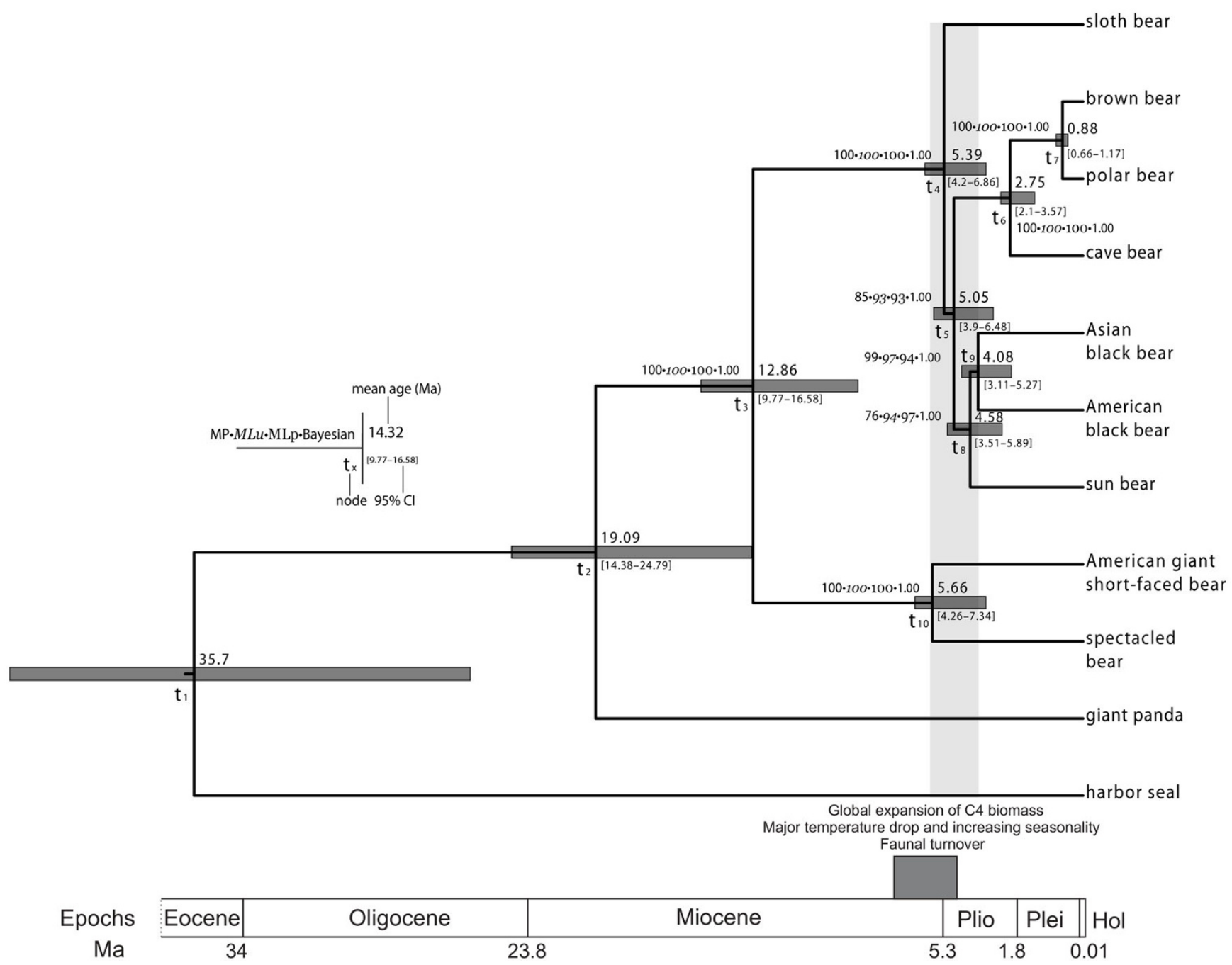

Figure I

Maximum clade probability tree displayed as a chronogram from the BEAST analysis of the unpartitioned mitochondrial genome alignment. All lineages evolved according to a strict clock and the GTR $+\Gamma_{4}$ substitution model. Numbers above the nodes indicate phylogenetic support measures. Node bars illustrate the width of the $95 \%$ highest posterior density. Numbers in bold indicate the posterior mean estimates of divergence times.

mated to have happened between 17.9 and $22.1 \mathrm{Ma}$ (range of posterior means across analyses). The next divergence was that of the New World spectacled bear group, which separated from the main ursine bear lineage about 12.4 to $15.6 \mathrm{Ma}$. The posterior mean divergence of the two New World species, the extant spectacled and the extinct American giant short-faced bear, was estimated to have happened between 5.3 and $7 \mathrm{Ma}$. Within the remaining ursine bears, the estimated divergence times all show overlapping confidence intervals, except for those within the brown bear clade.

Within the brown bear clade, we dated the divergence event between the cave and brown bear mtDNA to 2.4-
3.1 Ma. The origin of the polar bear is more difficult to determine, as partial mtDNA sequences suggest that polar bears actually fall within the genetic diversity spectrum of brown bears [20,21], where they constitute a monophyletic clade closely related to a clade of brown bears from the ABC Islands in Alaska. Unfortunately, the published brown bear mtDNA [10] does not originate from this ABC Island clade, and therefore our estimated divergence for polar bears and brown bears is not a minimum date for this event, but rather the divergence date for different brown bear clades. As a consequence, the estimated divergence date of 2.7 and 1.3 Ma for brown and polar bears obtained in two recent studies $[4,19]$ using the same complete mtDNAs should be interpreted with care. A 

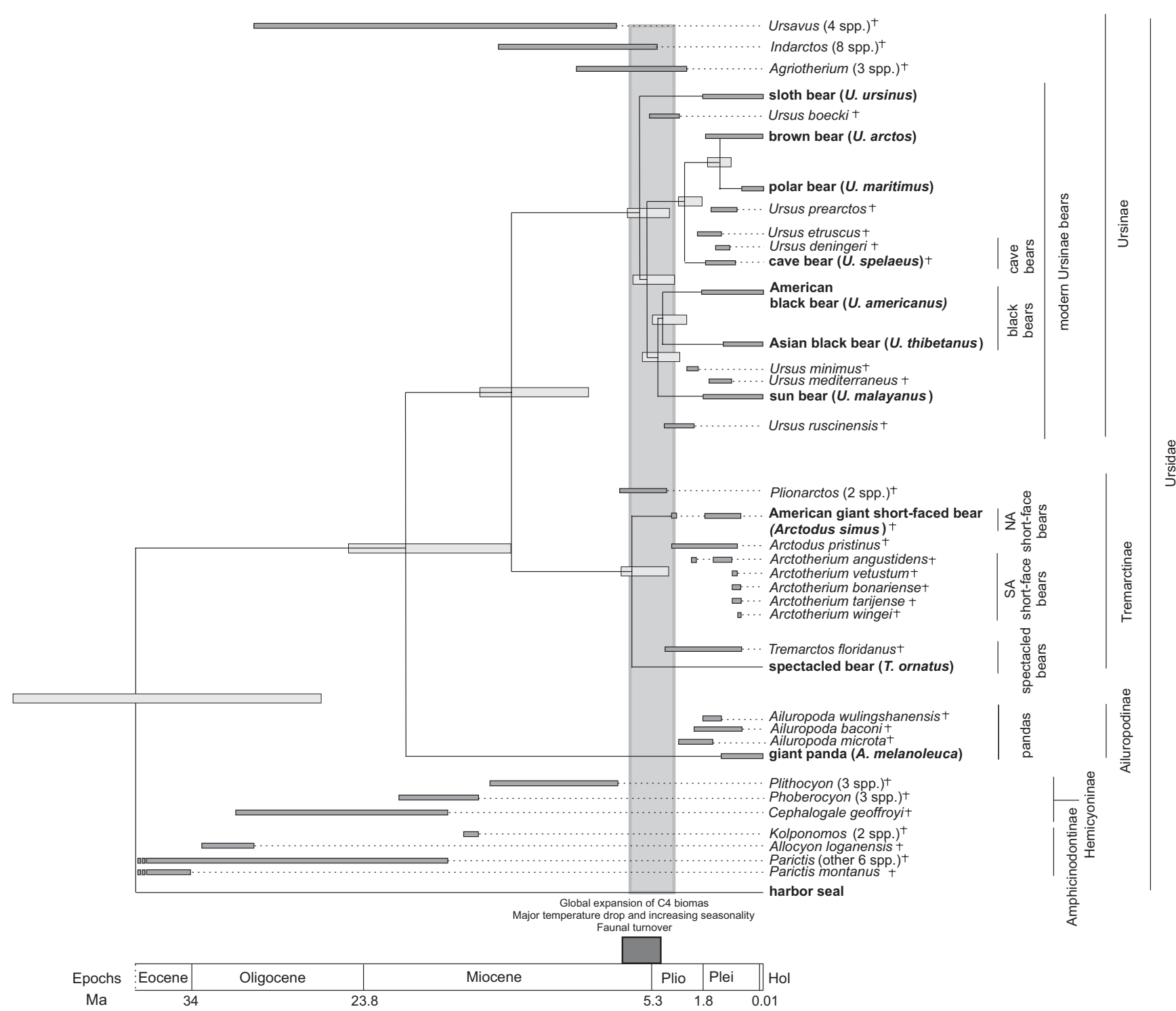

Figure 2

Temporal ranges of extant and fossil bears. Extinct genera and species are denoted with a cross $(\dagger)$. Species used in this study are written in bold. Horizontal dark grey bars indicate temporal range based on fossil evidence. Horizontal light grey bars show width of the $95 \%$ credibility interval for the molecular divergence time (see also Figure I). The vertical grey bar illustrates the range of the posterior mean estimate of divergence times for all extant ursine bears (expect polar and brown bear) as well as American giant short-faced bear and spectacled bear. The dark grey box illustrates a time interval of massive global changes around the Miocene- Pliocene boundary.

mtDNA from an ABC island brown bear will be required to date the actual speciation event of polar bears more accurately.

We also examined whether more sequence data would improve our estimates on divergence times by plotting the posterior means of divergence times against the width of their corresponding 95\% credibility interval (see Additional File 1, Figure S3), following Yang and Rannala [22].
We found significant correlations for both the unpartitioned and partitioned datasets $\left(p<2.2 \times 10^{-16}\right)$. This linear relationship strongly suggests that longer sequences or more taxa than those examined here are unlikely to increase the precision of the divergence time estimates. Therefore, in order to narrow the confidence intervals for the divergence date estimates within the bear phylogeny, more precisely dated fossil calibration points would be required. 
Table 3: Posterior estimates of divergence times.

\begin{tabular}{|c|c|c|c|c|c|c|}
\hline \multirow[t]{3}{*}{ Node } & \multicolumn{4}{|c|}{ Unpartitioned } & \multirow{2}{*}{\multicolumn{2}{|c|}{$\begin{array}{l}\text { Partitioned } \\
\text { mcmctree }\end{array}$}} \\
\hline & \multicolumn{2}{|r|}{ BEAST } & \multicolumn{2}{|r|}{ mcmctree } & & \\
\hline & Mean & $95 \%$ HPD & Mean & $95 \%$ HPD & Mean & $95 \%$ HPD \\
\hline$t_{1}$ & 35.69 & $26.55-46.51$ & 36.59 & $30.71-42.63$ & 36.49 & $31.20-47.40$ \\
\hline$t_{2}$ & 19.09 & $14.38-24.79$ & 22.05 & $18.37-25.57$ & 17.88 & $15.13-23.23$ \\
\hline$t_{3}$ & 12.86 & $9.77-16.58$ & 15.57 & $12.93-17.99$ & 12.36 & $10.44-15.97$ \\
\hline$t_{4}$ & 5.39 & $4.20-6.86$ & 6.31 & $5.23-7.14$ & 4.88 & $4.17-6.37$ \\
\hline$t_{5}$ & 5.05 & $3.90-6.48$ & 5.80 & $4.8 I-6.64$ & 4.55 & $3.85-5.99$ \\
\hline$t_{6}$ & 2.75 & $2.10-3.57$ & 3.11 & $2.55-3.63$ & 2.41 & $2.01-3.23$ \\
\hline$t_{7}$ & 0.88 & $0.66-1.17$ & 0.97 & $0.78-1.16$ & 0.75 & $0.61-1.00$ \\
\hline$t_{8}$ & 4.58 & $3.51-5.89$ & 5.31 & 4.39-6.II & 4.11 & $3.44-5.38$ \\
\hline$t_{9}$ & 4.08 & $3.11-5.27$ & 4.69 & $3.86-5.43$ & 3.66 & $3.07-4.84$ \\
\hline$t_{10}$ & 5.66 & $4.26-7.34$ & 6.98 & $5.73-8.18$ & 5.33 & $4.43-7.00$ \\
\hline rate & 1.199 & $0.896-1.50$ & 1.07 & $0.92-1.28$ & $\mathrm{AF}$ & $\mathrm{AF}$ \\
\hline$\kappa$ & - & - & 35.72 & $33.01-38.63$ & $\mathrm{AF}$ & $\mathrm{AF}$ \\
\hline$\alpha$ & 0.155 & $0.146-0.163$ & 0.20 & $0.19-0.21$ & $\mathrm{AF}$ & $\mathrm{AF}$ \\
\hline
\end{tabular}

The two mcmctree columns correspond to the unpartitioned and partitioned analyses. The divergence time estimates are in millions of years before present. HPD, highest posterior density; rate, evolutionary rate $\left(\times 10^{-8}\right.$ substitutions/site/year); $\kappa$, transition-transversion parameter of the HKY model; $\alpha$, shape parameter of the rate heterogeneity $\Gamma$-distribution. AF, see Additional File I.

The estimated substitution rate of approximately $10^{-8}$ substitutions/site/year was more similar to a mitogenomic dataset from primates than to the rate from extant and extinct proboscideans [9]. This evolutionary rate was also higher than that for parts of the nuclear IRBP gene in bears $\left(0.139 \times 10^{-8}\right.$ substitutions/site/year; [17]) .

\section{Discussion}

Our study represents the first comprehensive sampling of mtDNAs for recent bears, including all living and two recently extinct bear species. The cave bear and the American giant short-faced bear are the third and fourth Pleistocene species for which mtDNAs have been determined. Moreover, the cave bear genome is the first determined from a Pleistocene sample obtained from a non-permafrost environment. Compared to the extinct moas from which complete mtDNAs have previously been determined from non-permafrost specimens [23], the cave bear genome extends the time frame by an order of magnitude, showing that complete mtDNA analysis can be performed using a wide range of samples. As is common in large scale ancient DNA analyses $[7,9,24]$, we found a number of consistent differences between independent primary PCRs, all of which were either $\mathrm{C}$ to $\mathrm{T}$ or $\mathrm{G}$ to A substitutions (see Additional File 1). This confirms previous reports that deamination of cytosine is one of the most common, and probably the only type of miscoding lesion in ancient DNA [13,24-26]. Moreover, the high number of consistent substitutions (81) observed in the cave bear genome sequences shows that each sequence position needs to be replicated when performing such large scale analyses.
This analysis has allowed the phylogenetic topology of the bear family to be resolved with high support values. Interestingly, it places the sloth bear basal to all other ursine bear species and the sun bear in a sister group related to the two black bear species. The latter observation coincides with paleontological information [27] and previous mtDNA studies $[4,17,21]$. An earlier study analysing six mtDNA fragments, also placed the sloth bear basal to all other members of the ursine bears [3]. However, this study found weak support for the sun bear as being basal to the brown bear - polar bear clade rather than to the two black bear species.

The phylogenetic reconstruction also reveals the reasons for previous problems in resolving the relationships among ursine bears, as most of the internal branches for their phylogenetic tree are very short. Such a short internal branch structure (Figure 1) makes it likely that individual nuclear genes (or short sequences) may exhibit different tree topologies, as shown for nuclear loci from humans, chimpanzees and gorillas [18]. Furthermore it was previously shown that despite being a non-recombining single genetic locus, individual genes on the mtDNA might produce different tree topologies $[6,8,9,18]$.

The mitogenomic data also has implications for bear taxonomy. Six ursine bears and the sloth bear are monophyletic with absolute support, which agrees with Hall and Nowak's inclusion (Table 1) of the Asian black bear, American black bear, sun bear, polar bear and brown bear within the genus Ursus $[28,29]$ and confirms the mitogenomic study by $\mathrm{Yu}$ et al [4]. Given the short divergence 
time of the six ursine bears and the sloth bear we suggest, following Hall 1981, Nowak 1991 and Yu et al 2007 $[4,28,29]$, that the sloth bear is grouped together with the other ursine bears in the genus Ursus and that the other genus names previously suggested for members of this radiation are discarded (Table 1 ).

Using this data set and multiple fossil calibration points, we have dated the various mtDNA divergence events during bear evolution with reasonable confidence. Strikingly, the divergence of the giant panda is estimated at about 19 Ma (95\% HPD: 14.4-24.8 Ma, HPD: highest posterior density). This estimate is much earlier than previously reported for the divergence of the panda lineage from the Ursavus lineage based on teeth morphology of Agriarctos fossils (12-15 Ma) [30]. The latter divergence date has been used in several studies as a calibration point for dating bear radiations $[2,4,35]$. We decided not to use this date as a calibration point, since the oldest known panda fossil, Ailuropoda microta, is less than 2.4 million years old [31], and therefore allows no inference about the date of divergence of this lineage. Moreover, the fossil record for both Ailuropoda and its potential ancestral species from the genus Agriarctos is sparse, making an early Miocene divergence date for the giant panda's lineage plausible. Interestingly, the next divergence event is not until $13 \mathrm{Ma}$ (spectacled and American giant short-faced bear) followed by a gap until $6 \mathrm{Ma}$ when a rapid radiation occurs. The American giant short-faced and spectacled bears diverged around $5.7 \mathrm{Ma}$, and the five ursine lineages diverged between 5.4 and 4.1 Ma (posterior mean age estimates) (Figures 1 and 2).

Thus, taking the confidence intervals for the molecular dating into account, seven lineages radiated between 3.7 and $7 \mathrm{Ma}$. Such rapid radiations are also observed in other mammals, such as the cats [32] and procyonids [33], as well as in bird families like the woodpeckers [34]. Strikingly, the major radiation wave for these families also occurred at the end of the Miocene. In combination with the fossil record, the mtDNA divergence estimates suggest that the rapid radiation of the bear family around the Miocene-Pliocene boundary followed a major extinction of some of the main bear genera such as Ursavus, Indarctos, Agriotherium, and the Hemicyoninae (Figure 2). Similar species turnover events were also observed for other mammals over a limited time span near the Miocene-Pliocene boundary resulting in a massive extinction of more than $60-70 \%$ of all Eurasian genera and $70-80 \%$ of North American genera [35]. The cause of this widespread species turnover during this time period remains unclear. Some studies suggest that the initial opening of the Bering Strait at the beginning of the Pliocene around 5.3 Ma caused a major separation of northern hemisphere habitats [36]. Major climatic changes occurred during that time, such as the Messinian crisis during which the Mediterranean Sea lost its connection to the world ocean system and became desiccated [37]. These changes resulted in forest cover decline and the spread of arid habitats in Northern America and Eurasia [38,39] as well as a global increase in C4 biomass [40]. During that time, open grassland habitats, which were exploited by an entirely new suite of mammals [40], replaced the earlier less seasonal woodland forest habitats. Thus, it is possible that the environmental changes associated with the Miocene-Pliocene boundary and the following emergence of new ecological niches such as open grasslands caused an adaptive radiation in Old and New World bears similar to a number of other species groups [34]. This could explain the divergence of the Tremarctinae with the spectacled bear adapted to closed habitats and the American giant short-faced bears being predators dwelling in open habitats [12,27]. The latter adaptation was also described in other predator species that evolved around the Miocene-Pliocene boundary and were built for hunting in open habitats such as the cats [32,35]. Other events such as the opening of the Bering Strait could have additionally promoted allopatric speciation in black bears. Our divergence time estimates suggest that the American black bear could have spread to America before the Bering Strait opened around 5.3 Ma [36]. An early migration of ursine bears into the Americas is also supported by the oldest known Ursus fossil in North America, Ursus abstrusus [41], which was dated at $4.3 \mathrm{Ma}$, suggesting that $U$. abstrusus may be ancestral to the American black bear lineage.

Obviously, the Miocene-Pliocene global changes had a major impact on the radiation of bears and other species, both between and within the Old and New Worlds. It is interesting to note that African apes experienced a similar species turnover at the end of the Miocene, including the divergence of the chimpanzee and human lineages [42]. This latter event has been attributed to a magnified climatic variability starting at the end of the Miocene [43]. More studies are necessary to address the relationships between global changes and species radiations at the beginning of the Pliocene. Our results strongly support the idea of a major wave of bear radiations during that time.

Our data also indicate a much earlier divergence for the cave bear and brown bear lineages than those previously assumed, with a mean estimate at $2.8 \mathrm{Ma}$. This date agrees with recent results suggesting the existence of representatives of the brown bear lineage in Europe as early as 1.5 Ma (G. Rabeder, personal observation). Nevertheless, it questions other studies suggesting a later divergence time for this species pair at around 1.2-1.4 Ma based on the fossil record [27] and molecular data [44]. Loreille et al. [44], however, used Taberlet \& Bouvet's estimated diver- 
gence date for the two European brown bear lineages (Western and Eastern) of 850 ka [45], which in turn was based on an application of Vigilant et al.'s [46] intraspecific human rate of $8.4 \times 10^{-8}$ substitutions/site/year Taberlet \& Bouvet cautioned that their estimates could be prone to uncertainty as they imported a human evolutionary rate. Given recent reports of problems in estimated intraspecific divergence times based on interspecific calibrations and vice versa, the implicit use of indirectly extrapolated evolutionary rates is not recommended $[51,52]$.

Most of the youngest fossils for Ursus etruscus, the assumed ancestor of the cave and brown bear, have been dated to 2-2.7 Ma [47], suggesting that a late divergence for the two lineages around 1.2 $\mathrm{Ma}$ is rather unlikely. These dates also partially overlap with the divergence date we obtained (range of posterior means across methods: 2.4-3.1 Ma). A greater number of reliably dated fossils from early members of both the cave bear and brown bear lineages are necessary to date the divergence of $U$. spelaeus. However, around $2.8 \mathrm{Ma}$, the climate again changed dramatically with the onset of the first major cooling events and climatic oscillations at the end of the Pliocene that eventually led to the Pleistocene glaciations [48]. Thus, if bear speciation events were influenced by climate change, cave bears and brown bears may indeed have separated as early as $2.8 \mathrm{Ma}$.

\section{Conclusion}

Using complete mitochondrial genome sequences from both extinct and extant bears, we found evidence for a rapid radiation of bears at the Miocene - Pliocene Boundary 5-6 million years ago within the Old and New worlds. As rapid radiations were also observed in other species groups around this time [37-39], we suggest that climate change played an important role during bear evolution and animal speciation in general.

Our results clearly demonstrate the power of mitogenomic analyses for resolving complicated phylogenetic relationships among both extant and extinct species, using samples obtained not only from permafrost, but also from non-permafrost environments.

\section{Methods}

\section{Ancient and modern DNA samples}

The modern DNA samples of the Asian black bear, sloth bear and sun bear were obtained from DNA stocks held at the National Cancer Institute, Laboratory of Genomic Diversity in Frederick, Maryland (USA). The DNA samples of the giant panda and spectacled bear were obtained from the National Fish \& Wildlife Forensic Lab in Ashland, Oregon (USA).
In Leipzig, cave bear DNA was extracted from $640 \mathrm{mg}$ of bone powder taken from a femur found in Gamssulzen cave (Austria) that was dated to $44.160+1.400 /-1.190 \mathrm{BP}$ (KIA 25287). The extraction was performed as described previously [49], yielding $70 \mu \mathrm{l}$ of DNA extract. In Cambridge, $500 \mathrm{mg}$ of cave bear bone was extracted using the same protocol as in Leipzig. Details for the American giant short-faced bear DNA extraction performed in the Australian Centre for Ancient DNA can be found in Additional File 1.

\section{Multiplex amplification and sequencing}

Primer pairs were designed by aligning the three published mtDNAs of brown bear, polar bear and American black bear [10], and partial mtDNAs from various bear species retrieved from GenBank. The revised Cambridge reference sequence for the human mtDNA [50] was also included in the alignment. For the primers, regions were chosen that are highly conserved among bears, but carry substitutions compared to the modern human sequence, to minimize the risk of human contamination. As previously described for the 2-step multiplex protocol [7,51], the primer pairs for the first and second step were divided into two sets, ODD and EVEN, to avoid amplifying the overlapping fragments between adjacent products. The two primer sets were used in separate 2-step multiplex PCRs, as previously described [7]. The first amplification step was performed in a total volume of $20 \mu \mathrm{l}$. Each reaction contained a final concentration of $1 \mathrm{x}$ PCR-buffer, 4 $\mathrm{mM} \mathrm{MgCl}_{2}, 250 \mu \mathrm{M}$ of each dNTP, $150 \mathrm{nM}$ of each primer from one set and $2 \mathrm{U}$ AmpliTaq ${ }^{\varpi}$ Gold DNA polymerase plus $5 \mu \mathrm{l}$ of the DNA extract. PCRs were initiated by exposure to $94^{\circ} \mathrm{C}$ for $9 \mathrm{~min}$, followed by 25 cycles of $20 \mathrm{~s}$ at $94^{\circ} \mathrm{C}, 30 \mathrm{~s}$ at $52^{\circ} \mathrm{C}$ and $1 \mathrm{~min}$ at $72^{\circ} \mathrm{C}$. At the end, a final 4-min extension at $72^{\circ} \mathrm{C}$ was performed. This amplification was then diluted 40 fold and $5 \mu$ of the dilution were used as a template in each of the single amplification reactions. Reagent concentrations were as described above, except that a single primer pair was used at a concentration of $1.5 \mu \mathrm{M}$ for each primer, and only $0.5 \mathrm{U}$ of DNA polymerase were used in each reaction. The PCR temperature profile was the same as in the first amplification step. Amplification products of the correct size for the two extinct bears were cloned using the TOPO TA cloning kit (Invitrogen), and a minimum of three clones were sequenced on an ABI3730 capillary sequencer (Applied Biosystems). For the modern samples, PCR products were either sequenced from both directions, or multiple clones were sequenced to ensure sequence accuracy. Primers for fragments that gave no product in the first amplification attempts were redesigned if the adjacent fragments showed substitutions in the primer site. The resulting primers were then used to amplify the remaining segments of the bear genomes. For the two extinct bear species, each position of the mtDNA was amplified at least 
twice from independent primary amplifications to ensure the authenticity of the sequence [13]. For the cave bear a nested primer design was chosen where the primers in the singleplex amplification are shifted inwards compared to the primers used in the multiplex step. This design ensures specificity of the singleplex PCR and reduces the risk of contamination of the multiplex PCR since only products from the singleplex reaction are amplified to high copy numbers [51]. All primer sequences used can be found in Additional File 1. For the sequenced modern bears and the cave bear primer sets EVEN and ODD are comprised of 20 primer pairs each. A single primer pair, EVEN21, spanning a repeat region within the D-loop, was excluded from both sets and only used in singleplex PCRs. For the Giant short faced-bear 81 primer pairs were designed in total and split into two sets; all amplification attempts spanning the repeat region within the D-loop for the American giant short-faced bear failed.

In Cambridge, amplifications were completed using the same PCR conditions as in Leipzig, but with a reduced number of primer pairs. Both water controls and an extraction control consisting of a mammoth DNA extract were negative for cave bear-specific products. Eighteen amplification products, originating from independent primary PCRs, were sequenced in both directions for 9 different fragments distributed throughout the whole mtDNA. A total of 3,520 bp were amplified and sequenced. The consensus sequences for all fragments were identical to the corresponding sequences produced in Leipzig.

For the American giant short-faced bear in total $395 \mathrm{bp}$ of the mtDNA were replicated in two fragments at the Australian Centre for Ancient DNA. Details can be found in Additional File 1.

\section{Mitochondrial genome sequence alignment and annotation}

The newly sequenced mtDNAs for the two extinct and five extant bear species, as well as the four publicly available genomes (three bears and a harbor seal) were aligned in MUSCLE 3.6 using the default parameters [52]. The Dloop was removed for all analyses, as it is too variable for interspecific comparisons and could partially not be determined from the American short-faced bear. We employed nine sequence data partitioning schemes in the following order: the transcription process; the three codon positions on each strand, the tRNAs on each strand and the rRNA genes. A few nucleotides were duplicated in the partitioned dataset because of the overlap of some loci, and a small number of non coding nucleotides were excluded. The annotation was completed using the program DOGMA [53] and modified manually to avoid overlap of tRNA and protein-coding genes.

\section{Phylogenetic analyses}

The substitution model was selected using Akaike's Information Criterion on all models available in the baseml program of PAML 3.15 [54]. For both the partitioned and the unpartitioned datasets, the GTR $+\Gamma$ [55-57] was found to be the best-fit model. This model was used in all subsequent analyses unless specified otherwise.

The phylogeny of the mtDNAs was reconstructed using a thorough maximum parsimony (MP) search that is implemented in TNT [58], with 500 random-addition sequences and a variety of tree space exploration techniques. We also employed maximum likelihood (ML) in RAxML 2.2.3 [59], as well as a Bayesian inference (BI) of phylogeny in MrBayes 3.1.2 [60]. The GTR $+\Gamma_{4}$ substitution model was used for both ML and BI analyses. Phylogenetic support was provided with 1000 bootstrap pseudoreplicates in ML and 5,000 replicates of symmetric resampling in MP. MrBayes was run twice for 3 million generations with a burn-in of 2,500 steps. For details, see Additional File 1.

Incongruence between individual partitions was evaluated in an MP framework employing variations of Bremer support measures, as implemented in Automated Simultaneous Analysis of Phylogenies [61], as well as with the ILD test [62]. Agreement or disagreement between individual partitions at each node in the mtDNA tree was expressed through positive and negative hidden branch support (HBS) values, respectively [63]. See Additional File 1 for further details.

\section{Contrasting alternative phylogenetic hypotheses}

We collected 10 alternative topologies on the phylogenetic relationships of bears from the available literature (see Additional File 1, Figure S2) and compared them in an ML framework using the approximately unbiased test (AU) [64] in CONSEL [65], along with a comparison of homoplasy indices and tree lengths.

\section{Estimation of divergence times}

Dating of the divergence events within bears was done using a molecular clock approach and several fossil calibration points. The minimum for the divergence of bears and seals was set to $33.9 \mathrm{Ma}$, based on the fossil species Parictis montanus [66] and Parictis parvus [67] both dated to 38-33.9 Ma, and the first well-described members on the bear lineage. As a second calibration point, the minimum age for the oldest described Ursus fossils, U. minimus and $U$. ruscinensis, at 4.2 Ma [47] was used, and the maximum for the youngest fossils from the genus Ursavus, $U$. depereti and U. ehrenbergi, which gave rise to the Ursus lineage [11], at 7.1 Ma [47]. 
The above mentioned calibration points were used as priors to obtain the posterior distribution of the estimated divergence times. Evolutionary rate constancy according to a molecular clock for all bear mtDNAs, including the harbor seal outgroup, was tested using a likelihood ratio test (LRT) in baseml [68]. The assumption of a molecular clock at the $1 \%$ level under a GTR $+\Gamma$ model for the whole mtDNA alignment excluding the D-loop for the partitioned $(-2 \delta L=14.3, p=0.112)$ and unpartitioned $(-2 \delta L=$ $18.0, p=0.036)$ dataset could not be rejected.

We estimated divergence times using two Bayesian approaches implemented in the programs momctree [54] and BEAST 1.4.4 [69]. Mcmctree was run using the HKY $85+\Gamma_{8}$ substitution model $[57,70]$, the most parameter-rich model available in this program. A total of $10^{5}$ generations were sampled every 5 steps after discarding $10^{4}$ initial steps as burn-in. The more parameter-rich model GTR $+\Gamma_{4}$ was used in BEAST with the following priors: Yule speciation prior on the tree, siteModel.alpha (initial $=0.2$, exponential prior with mean 1.0 and $95 \%$ CI of 0.05129-2.996), clock.rate (initial $=0.015$, uniform prior of 0-10), root.height of ursine bear clade (uniform prior of 7.1-4.2 Ma based on the basal ursine bear radiation fossil data). Thirty million Markov chain Monte Carlo (MCMC) steps were sampled every 1,000 generations. Convergence was assessed in Tracer v1.3 [71] after excluding the first 5 million samples as burn-in. All effective sample size values exceeded 20,000, suggesting a sufficient run length. The strict clock was implemented in all divergence time estimations, as suggested by the LRT.

\section{Authors' contributions}

JK, TU, AN, AWB, SJB, PHD, HS and MS were responsible for the experimental work. JK, ASM and SOK performed the sequence and evolutionary analyses. GR and PM obtained the ancient bear specimens and arranged the dating. LS contributed paleontological information on the bear fossil record. SJO provided extant bear DNA. AC, $\mathrm{SP}, \mathrm{JK}, \mathrm{MSlatkin}$ and $\mathrm{MH}$ conceived ideas for this project. $\mathrm{JK}, \mathrm{ASM}, \mathrm{SOK}$ and MH wrote the manuscript. All authors read and approved the final draft.

\section{Additional material}

\section{Additional File 1}

Supplementary materials.

Click here for file

[http://www.biomedcentral.com/content/supplementary/1471-

2148-8-220-S1.doc]

\section{Acknowledgements}

$\mathrm{SB}$ and $\mathrm{AC}$ were supported by the ARC, and gratefully acknowledge the assistance of the Canadian Museum of Nature, and D. Harington for the sample of the Arctodus specimen. We thank S. Giesser for help with the species distribution map design. JK, TU, AN, MS, AWB, SP and MH thank the Max Planck Society for financial support. SOK was supported by an AMNH Conservation Genetics Research Fellowship. ASM and MSlatkin were supported by $\mathrm{NIH}$ grant ROI-GM40282.

\section{References}

I. Fulton TL, Strobeck C: Molecular phylogeny of the Arctoidea (Carnivora): effect of missing data on supertree and supermatrix analyses of multiple gene data sets. Mol Phylogenet Evol 2006, 4I: I65-I8I.

2. Talbot SL, Shields GF: A phylogeny of the bears (Ursidae) inferred from complete sequences of three mitochondrial genes. Mol Phylogenet Evol 1996, 5:567-575.

3. Waits LP, Sullivan J, O'Brien SJ, Ward RH: Rapid radiation events in the family Ursidae indicated by likelihood phylogenetic estimation from multiple fragments of mtDNA. Mol Phylogenet Evol 1999, I3:82-92.

4. Yu L, Li YW, Ryder OA, Zhang YP: Analysis of complete mitochondrial genome sequences increases phylogenetic resolution of bears (Ursidae), a mammalian family that experienced rapid speciation. BMC Evol Biol 2007, 7:198.

5. McKenna MC, Bell SK: Classification of Mammals above the Species Level New York: Columbia University Press; 1997.

6. Cummings MP, Otto SP, Wakeley J: Sampling properties of DNA sequence data in phylogenetic analysis. Mol Biol Evol 1995, I 2:814-822.

7. Krause J, Dear PH, Pollack JL, Slatkin M, Spriggs H, Barnes I, Lister AM, Ebersberger I, Paabo S, Hofreiter M: Multiplex amplification of the mammoth mitochondrial genome and the evolution of Elephantidae. Nature 2006, 439:724-727.

8. Rogaev EI, Moliaka YK, Malyarchuk BA, Kondrashov FA, Derenko MV, Chumakov I, Grigorenko AP: Complete mitochondrial genome and phylogeny of Pleistocene mammoth Mammuthus primigenius. PLoS Biol 2006, 4:e73.

9. Rohland N, Malaspinas AS, Pollack JL, Slatkin M, Matheus P, Hofreiter $M$ : Proboscidean mitogenomics: chronology and mode of elephant evolution using mastodon as outgroup. PLOS Biol 2007, 5:e207.

10. Delisle I, Strobeck C: Conserved primers for rapid sequencing of the complete mitochondrial genome from carnivores, applied to three species of bears. Mol Biol Evol 2002, 19:357-36 I.

II. Kurten B: The Cave Bear Story, life and death of a vanished animal. New York: Columbia University Press; 1976.

12. Hunt RMJ: Ursidae. In Evolution of Tertiary Mammals of North America Volume I. Edited by: Janis CM, Scott KM, Jacobs LL. Cambridge: Cambridge University Press; 1998: I74- 195.

13. Hofreiter M, Jaenicke V, Serre D, Haeseler AvA, Pääbo S: DNA sequences from multiple amplifications reveal artifacts induced by cytosine deamination in ancient DNA. Nucleic Acids Res 2001, 29:4793-4799.

14. Delisle I, Strobeck C: A phylogeny of the Caniformia (order Carnivora) based on 12 complete protein-coding mitochondrial genes. Mol Phylogenet Evol 2005, 37:192-201.

15. Nash WG, O'Brien SJ: A comparative chromosome banding analysis of the Ursidae and their relationship to other carnivores. Cytogenet Cell Genet 1987, 45:206-2I2.

16. O'Brien SJ, Nash WG, Wildt DE, Bush ME, Benveniste RE: A molecular solution to the riddle of the giant panda's phylogeny. Nature 1985, 3 | 7: |40-144.

17. Yu L, Li QW, Ryder OA, Zhang YP: Phylogenetic relationships within mammalian order Carnivora indicated by sequences of two nuclear DNA genes. Mol Phylogenet Evol 2004, 33:694-705.

18. O'Huigin C, Satta Y, Takahata N, Klein J: Contribution of homoplasy and of ancestral polymorphism to the evolution of genes in anthropoid primates. Mol Biol Evol 2002, I9:|50I-15I3.

19. Arnason U, Gullberg A, Janke A, Kullberg M: Mitogenomic analyses of caniform relationships. Mol Phylogenet Evol 2007, 45:863-874.

20. Shields GF, Adams D, Garner G, Labelle M, Pietsch J, Ramsay M, Schwartz C, Titus K, Williamson S: Phylogeography of mitochondrial DNA variation in brown bears and polar bears. Mol Phylogenet Evol 2000, I5:319-326. 
21. Talbot SL, Shields GF: Phylogeography of brown bears (Ursus arctos) of Alaska and paraphyly within the Ursidae. Mol Phylogenet Evol 1996, 5:477-494.

22. Yang Z, Rannala B: Bayesian estimation of species divergence times under a molecular clock using multiple fossil calibrations with soft bounds. Mol Biol Evol 2006, 23:212-226.

23. Cooper A, Lalueza-Fox C, Anderson S, Rambaut A, Austin J, Ward R: Complete mitochondrial genome sequences of two extinct moas clarify ratite evolution. Nature 200I, 409:704-707.

24. Stiller M, Green RE, Ronan M, Simons JF, Du L, He W, Egholm M, Rothberg JM, Keates SG, Ovodov ND, Antipina EE, Baryshnikov GF, Kuzmin YV, Vasilevski AA, Wuenschell GE, Termini J, Hofreiter M, Jaenicke-Despres V, Paabo S: Patterns of nucleotide misincorporations during enzymatic amplification and direct large-scale sequencing of ancient DNA. Proc Natl Acad Sci USA 2006 , 103: 13578-13584.

25. Briggs AW, Stenzel U, Johnson PL, Green RE, Kelso J, Prufer K, Meyer M, Krause J, Ronan MT, Lachmann M, Paabo S: Patterns of damage in genomic DNA sequences from a Neandertal. Proc Natl Acad Sci USA 2007, 104:|4616-|462I.

26. Brotherton P, Endicott P, Sanchez J], Beaumont M, Barnett R, Austin J, Cooper A: Novel high-resolution characterization of ancient DNA reveals $\mathbf{C}>\mathbf{U}$-type base modification events as the sole cause of post mortem miscoding lesions. Nucleic Acids Res 2007, 35:5717-5728.

27. Kurten B, Anderson E: Pleistocene Mammals of North America New York: Columbia University Press; 1980.

28. Hall ER: The Mammals of North America 2nd edition. New York: Ronald Press; 1981.

29. Nowak RM: Walker's Mammals of the World Volume 2. 5th edition. Baltimore: Johns Hopkins University Press; 1991.

30. Thenius E: Zur systematischen und phylogenetischen Stellung des Bambusbaeren: Ailuropoda melanoleuca. Z Saugetierk 1979 44:286-305.

31. Jin C, Ciochon RL, Dong W, Hunt RM Jr, Liu J, Jaeger M, Zhu Q: The first skull of the earliest giant panda. Proc Natl Acad Sci USA 2007, 104: 10932-10937.

32. Johnson WE, Eizirik E, Pecon-Slattery J, Murphy WJ, Antunes A, Teeling E, O'Brien SJ: The late Miocene radiation of modern Felidae: a genetic assessment. Science 2006, 3II:73-77.

33. Koepfli KP, Gompper ME, Eizirik E, Ho CC, Linden L, Maldonado JE, Wayne RK: Phylogeny of the Procyonidae (Mammalia: Carnivora): molecules, morphology and the Great American Interchange. Mol Phylogenet Evol 2007, 43: 1076-1095.

34. Fuchs J, Ohlson JI, Ericson PGP, Pasquet E: Synchronous intercontinental splits between assemblages of woodpeckers suggested by molecular data. Zool Scripta 2007, 36: I I-25.

35. Van Valkenburgh B: Major patterns in the history of carnivorous mammals. Annu Rev Earth Planet Sci 1999, 27:463-493.

36. Marincovich L Jr, Gladenkov AY: Evidence for an early opening of the Bering Strait. Nature 1999, 397:|49-|5I.

37. Hsü KJ, Montadert L, Bernoulli D, Cita MB, Erickson A, Garrison RE, Kidd RB, Mélières F, Müller C, Wright RH: History of the Mediterranean salinity crisis. Nature 1977, 267:399-403.

38. Fortelius M, Eronen J, Liu L, Pushkina D, Tesakov A, Vislobokova I, Zhang Z: Late Miocene and Pliocene large land mammals and climatic changes in Eurasia. Palaeogeogr Palaeoclimatol Palaeoecol 2006, 238:

39. Janis CM: Tertiary mammal evolution in the context of changing climates, vegetation and tectonic events. Annu Rev Ecol Syst 1993, 24:467-500

40. Cerling TE, Ehleringer JR, Harris JM: Carbon dioxide starvation, the development of $\mathrm{C} 4$ ecosystems, and mammalian evolution. Philos Trans R Soc Lond B Biol Sci 1998, 353:159-170. discussion $|70-15|$

41. Gustafson PE: The vertebrate faunas of the Pliocene Ringold Formation, south-central Washington. Univ OR Mus Nat Hist Bull 1978, 23: I-62.

42. Kumar S, Filipski A, Swarna V, Walker A, Hedges SB: Placing confidence limits on the molecular age of the human-chimpanzee divergence. Proc Natl Acad Sci USA 2005, 102: | 8842-18847.

43. Potts R: Environmental hypotheses of hominin evolution. $A m$ J Phys Anthropol 1998:93-136.

44. Loreille O, Orlando L, Patou-Mathis M, Philippe M, Taberlet P, Hanni $C$ : Ancient DNA analysis reveals divergence of the cave bear,
Ursus spelaeus, and brown bear, Ursus arctos, lineages. Curr Biol 200I, I I:200-203.

45. Taberlet P, Bouvet J: Mitochondrial DNA polymorphism, phylogeography, and conservation genetics of the brown bear Ursus arctos in Europe. Proc $R$ Soc Lond B Biol Sci 1994, 255: 195-200.

46. Vigilant L, Stoneking M, Harpending H, Hawkes K, Wilson AC: African populations and the evolution of human mitochondrial DNA. Science 199|, 253:1503-1507.

47. Neogene of the Old World - Database of Fossil Mammals (NOW) [http://www.helsinki.fi/science/now

48. Jansen E, Fronval T, Rack F, Channel JET: Pliocene-Pleistocene ice rafting history and cyclicity in the Nordic Seas during the last 3.5 Myr. Paleoceanography 2000, 1 5:709-72I.

49. Hofreiter M, Rabeder G, Jaenicke-Despres V, Withalm G, Nagel D, Paunovic $M$, Jambresic G, Pääbo $S$ : Evidence for reproductive isolation between cave bear populations. Curr Biol 2004, I 4:40-43.

50. Andrews RM, Kubacka I, Chinnery PF, Lightowlers RN, Turnbull DM, Howell N: Reanalysis and revision of the Cambridge reference sequence for human mitochondrial DNA. Nat Genet 1999, 23:147.

5I. Rompler H, Dear PH, Krause J, Meyer M, Rohland N, Schoneberg T, Spriggs $H$, Stiller M, Hofreiter M: Multiplex amplification of ancient DNA. Nat Protoc 2006, I:720-728.

52. Edgar RC: MUSCLE: multiple sequence alignment with high accuracy and high throughput. Nucleic Acids Res 2004, 32: $1792-1797$.

53. Wyman SK, Jansen RK, Boore JL: Automatic annotation of organellar genomes with DOGMA. Bioinformatics 2004, 20:3252-3255.

54. Yang Z: PAML: a program package for phylogenetic analysis by maximum likelihood. Comput Appl Biosci 1997, 13:555-556.

55. Lanave C, Preparata G, Saccone C, Serio G: A new method for calculating evolutionary substitution rates. I Mol Evol 1984 , 20:86-93.

56. Rodriguez F, Oliver JL, Marin A, Medina JR: The general stochastic model of nucleotide substitution. J Theor Biol I990, I42:485-50 I.

57. Yang Z: Maximum-likelihood estimation of phylogeny from DNA sequences when substitution rates differ over sites. Mol Biol Evol 1993, 10:1396-1401.

58. Goloboff $P$, Farris J, Nixon K: TNT, a free program for phylogenetic analysis. Cladistics 2008, 24: I-13.

59. Stamatakis A: RAxML-VI-HPC: maximum likelihood-based phylogenetic analyses with thousands of taxa and mixed models. Bioinformatics 2006, 22:2688-2690.

60. Ronquist F, Huelsenbeck JP: MRBAYES 3: Bayesian phylogenetic inference under mixed models. Bioinformatics 2003, 19:1572-1574.

6I. Sarkar IN, Egan MG, Coruzzi G, Lee EK, DeSalle R: Automated simultaneous analysis phylogenetics (ASAP): an enabling tool for phylogenomics. BMC Bioinformatics 2008, 9: 103.

62. Farris JS, Källersjö M, Kluge AG, Bult $C$ : Testing significance of incongruence. Cladistics 1994, 10:3 I5-319.

63. Gatesy J, O'Grady P, Baker RH: Corroboration among data sets in simultaneous analysis: hidden support for phylogenetic relationships among higher level artiodactyl taxa. Cladistics 1999, 15:27|-3/3.

64. Shimodaira $\mathrm{H}$ : An approximately unbiased test of phylogenetic tree selection. Syst Biol 2002, $51: 492-508$.

65. Shimodaira $H$, Hasegawa M: CONSEL: for assessing the confidence of phylogenetic tree selection. Bioinformatics 200I, I 7:1246-1247.

66. Clark J, Guensburg TE: Arctoid genetic characters as related to the genus Parictis. Fieldiana: Geology 1972, 26:1-76.

67. Clark J, Beerbower JR, Kietze KK: Oligocene sedimentation, stratigraphy, paleoecology, and paleoclimatology in the Big Badlands of South Dakota. Fieldiana Geol 1967, 5: I-158.

68. Felsenstein J: Evolutionary trees from DNA sequences: a maximum likelihood approach. J Mol Evol 1981, 17:368-376.

69. Drummond AJ, Rambaut A: BEAST: Bayesian evolutionary analysis by sampling trees. BMC Evol Biol 2007, 7:214.

70. Hasegawa M, Kishino H, Yano $T$ : Dating of the human-ape splitting by a molecular clock of mitochondrial DNA. J Mol Evol 1985:160-174

7I. Rambaut A, Drummond AJ: Tracer vI.3. 2004 [http:// tree.bio.ed.ac.uk/software/tracer]. 
72. Eisenberg JF: The Mammalian Radiations Chicago: University of Chicago Press; 198I.

73. Ewer RF: The Carnivora Ithaca: Cornell University Press; 1973.

74. Corbet GB, Hill JE: A World List of Mammalian Species London: Oxford University Press; 1991.

75. Zhang YP, Ryder OA: Phylogenetic relationships of bears (the Ursidae) inferred from mitochondrial DNA sequences. Mol Phylogenet Evol 1994, 3:351-359.

76. Thenius E: Carnivores: phylogeny. In Grizmek's encyclopedia of mammals Volume 3. Edited by: Grizmek B. New York: McGraw Hill; 1990:370-464.

77. Wozencraft WC: Order Carnivora. In Mammal Species of the World: A taxonomic and geographic reference Volume 3. 3rd edition. Edited by: Wilson DE, Reeder DM. Baltimore: Johns Hopkins University Press; 2005:532-628.

Publish with Bio Med Central and every scientist can read your work free of charge

"BioMed Central will be the most significant development for disseminating the results of biomedical research in our lifetime. "

Sir Paul Nurse, Cancer Research UK

Your research papers will be:

- available free of charge to the entire biomedical community

- peer reviewed and published immediately upon acceptance

- cited in PubMed and archived on PubMed Central

- yours - you keep the copyright

Submit your manuscript here:

http://www.biomedcentral.com/info/publishing_adv.asp
BioMedcentral 